\title{
Diacronie
}

Studi di Storia Contemporanea

$N^{\circ} 16,4 \mid 2013$

Le monarchie nell'età dei nazionalismi

\section{Monarquía y patrimonio en tiempos de revolución en España}

Encarna García Monerris y Carmen García Monerris

\section{(2) OpenEdition}

Journals

\section{Edición electrónica}

URL: http://journals.openedition.org/diacronie/855

DOI: 10.4000/diacronie.855

ISSN: 2038-0925

\section{Editor}

Association culturelle Diacronie

\section{Referencia electrónica}

Encarna García Monerris y Carmen García Monerris, « Monarquía y patrimonio en tiempos de revolución en España », Diacronie [En línea], N 16, 4 | 2013, documento 4, Puesto en línea el 01 diciembre 2013, consultado el 30 abril 2019. URL : http://journals.openedition.org/diacronie/855 ; DOI : 10.4000/diacronie.855 


\title{
Diacronie
}

\section{Monarquía y patrimonio en tiempos de revolución en España}

\author{
Encarna GARCÍA MONERRIS, Carmen GARCÍA MONERRIS*
}

Este artículo plantea las relaciones existentes entre el Real Patrimonio y la Monarquía española a lo largo del siglo XIX, como manifestación de un permanente conflicto y debate político, pero también como expresión de la confrontación de dos legitimidades y de dos referentes: el histórico y el estrictamente político. La Corona española contribuyó en manera muy escasa a la necesaria reubicación de esta vieja institución en el nuevo ordenamiento político y jurídico liberal. Su empeño por mantener un patrimonio de dudosa naturaleza y titularidad como privado trascendió el ámbito plenamente "doméstico" y se solapó con el más público y político de asignación de la "lista civil" y del proyecto soberanista, ya esbozado en las Cortes de Cádiz, de una nacionalización y desamortización de los bienes del Real Patrimonio. Fue un factor no despreciable de descrédito, cuando menos de la dinastía de los Borbones.

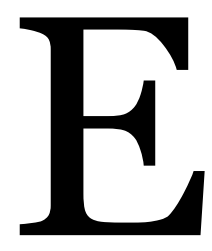

1 impulso inicial de los procesos revolucionarios liberales desde el setecientos contenía un generalizado carácter reformista y antidespótico, pero no necesariamente antimonárquico. Si prescindimos de las experiencias iberoamericanas (y con muchos matices), las contadas excepciones, tanto en Europa como en América del Norte, confirmarían la regla general de un proceso que, como afirma Langewiesche, hizo del ochocientos «el siglo burgués, el siglo de la nación y del Estado nacional», pero también «el siglo de la monarquía»․․ España no fue un

Este trabajo forma parte del proyecto de investigación FFI2008-02107, de la Secretaría de Estado de Universidades del Ministerio de Ciencia e Innovación, "La monarquía liberal en España: culturas, discursos y prácticas políticas (1833-1885)».

${ }^{1}$ LANGEWIESCHE, Dieter, La época del Estado-Nación en Europa, Valencia, PUV, 2012, p. 120 (edición a cargo de Jesús Millán y $\mathrm{M}^{\mathrm{a}}$ Cruz Romeo). A propósito del origen y procesos de formación de los Estados iberoamericanos en el primer tercio del siglo XIX: CHUST, Manuel, 
caso aparte: el primer proyecto liberal gaditano contempló la monarquía como forma de Estado, sin que ello, como tendremos ocasión de ver, le garantizara ni la permanencia ni una sólida base de legitimidad a lo largo de los agitados años de la revolución y de la post revolución.

La Constitución de 1812, en un peculiar contexto de ruptura institucional y de crisis de soberanía, supo incorporar de manera admirable todo el amplísimo lenguaje antidespótico de la Ilustración tardía y configurar un sentido de nación política que se desgajaba nítidamente de los resabios patrimonialistas del absolutismo. En este sentido, la monarquía fue reubicada en el nuevo entramado institucional a costa de perder su vieja legitimidad histórica, religiosa, "natural", y justificarse como poder constituido por la voluntad soberana de una nación que no se reconocía como propiedad de ninguna familia ${ }^{2}$. La nación se rescataba a sí misma y desde su autonomía apartaba al monarca de su tradicional patrimonialismo para convertirlo en un poder más, sustentado económicamente por la denominada "lista civil", o contribución que esa misma nación destinaba a sus necesidades y mantenimiento propio y de su familia. Desde este punto de vista, aquello que en la tradición española era conocido como «Patrimonio Real»3 debía ser abolido, configurándose la nación como la nueva titular de sus derechos, bienes y regalías, y destinando o reservando al monarca y a su familia aquellos lugares simbólicos y necesarios para el decoro y desempeño de su alta misión. Tal fue el sentido del inaplicado decreto de Cortes de 28 de marzo de 1814 que señalaba indudablemente el carácter constituido de la institución monárquica. Sin embargo, y

FRASQUET, Ivana, Tiempos de revolución. Comprender las independencias iberoamericanas, Madrid, Taurus/MAPFRE, 2013.

${ }^{2}$ En el artículo $2^{\mathrm{o}}$ de la Constitución gaditana se afirmaba que la nación «no es ni puede ser patrimonio de ninguna familia ni persona». La bibliografía sobre Cádiz y el primer constitucionalismo español es ya abundante y plural, sobre todo a partir de las revisiones realizadas con ocasión de la conmemoración del Bicentenario. A título de ejemplo, y también como síntesis pueden consultarse el número monográfico de la revista Teoría y Derecho. Revista de Pensamiento Jurídico : La Constitución de 1812. Miradas y perspectivas, 10, 2011; el trabajo del profesor VARELA SUANZES-CARPEGNA, Joaquín, La monarquía doceañista (1810-1837), Madrid, Marcial Pons, 2013.

3 En el caso español quedaron tempranamente diferenciados los bienes patrimoniales pertenecientes a los monarcas en los países de la antigua Corona de Aragón, que tuvieron desde el principio un carácter vinculado a la institución monárquica, al tiempo que una morfología más señorial y arcaizante, de los de la Corona de Castilla, nutridos básicamente a partir de adquisiciones de la monarquía de bosques, palacios, jardines, cotos, etc. En conjunto el patrimonio regio acabó configurando un entramado de bienes, derechos y regalías, con una compleja y plural administración que pervivió hasta bien avanzado el siglo XIX, generadora de serios conflictos sociales y políticos y que, pese a su más que dudosa rentabilidad económica, fue permanentemente reivindicada como propiedad privada por los Borbones en pugna con los derechos de la nación. Hemos trabajado la conflictiva relación entre la Nación y la dinastía de los Borbones a lo largo del siglo XIX, a propósito del destino del patrimonio regio, en un libro de próxima aparición titulado Monarquía, liberalismo y Real Patrimonio. Historia política de una larga desavenencia (1808-1874). 
como manifestación ya temprana de las profundas tensiones que el tema del patrimonio regio iba a generar, el propio decreto introducía una tercera perspectiva historicista por la que se señalaba un patrimonio privado del rey que debía resultar del análisis y expurgación de los documentos y títulos existentes en el archivo de Palacio y de las distintas Secretarías de Estado.

Aunque de ningún efecto por el golpe de estado absolutista de mayo de 1814, lo cierto es que este decreto marcó como ningún otro el cúmulo de contradicciones y sobre todo de proyectos diversos que se cernirían sobre la institución del Real Patrimonio. A lo largo de la centuria, las voces de los progresistas y de los moderados, en momentos y coyunturas varias, darían buena cuenta de un problema que, como un mal sueño, acompañó a la trayectoria de la institución monárquica y del proprio Estado liberal en España. Con todo, ésta fue la primera oportunidad perdida.

La vuelta de Fernando VII en 1814 introdujo un giro espectacular en las intenciones soberanistas de las Cortes gaditanas. A partir sobre todo de 1816, el monarca absoluto reafirmó el carácter privado del Patrimonio Real en un movimiento que le distanciaba incluso de las tendencias patrimonialistas del setecientos, y procedió a una separación nítida entre la administración de la Casa Real y Patrimonio y la del Estado. Su reafirmación como propietario no ocultaba su pretensión de un universalismo patrimonialista que iba a implicar el mantenimiento de una jurisdicción privativa sobre sus dominios frente a los generales de la nación y, en consecuencia, una capacidad nunca ocultada de recuperar supuestos derechos perdidos o usurpados por terceros, especialmente nobleza y corporaciones municipales. Incluso los sectores más conservadores de la sociedad en esos momentos, encarnados en los Grandes de España, denunciaron esta amenaza 4 .

Ambas opciones, la soberanista (aplicada de nuevo entre 1820 y 1823) y la patrimonial privativa (recuperada desde 1823 hasta la muerte del rey en 1833) se convertirían en los dos referentes fundamentales en conflicto a lo largo de todo el siglo XIX, durante y después de la revolución. Desde la regencia de María Cristina (18331840), viuda del monarca, la relación entre la monarquía y el liberalismo se tornó de recíproca necesidad, entre otras razones por la cruenta guerra civil desencadenada por

$4 \mathrm{El}$ decreto de 28 de marzo de 1814 in Colección de los Decretos y Ordenes que han expedido las Cortes Ordinarias (desde 25 de septiembre de 1813 hasta 11 de mayo de 1814), Madrid, Imprenta Nacional, 1821, pp. 148-150. Un desarrollo más extenso del tema del Real Patrimonio y el primer liberalismo en nuestro artículo: Carmen GARCÍA MONERRIS, Encarna GARCÍA MONERRIS, «La Nación y su dominio: el lugar de la Corona», in Historia Constitucional, 5, 2004,

URL: <http://www.historiaconstitucional.com/index.php/historiaconstitucional/issue/view/6> [consultado el 15 de septiembre 2013]. 
la cuestión sucesoria que planteó el carlismo como opción antiliberal. Ello no impidió, no obstante, que la regente se mostrara como fiel continuadora del empuje patrimonialista de su marido, herencia a preservar para la sucesora en el trono, su hija Isabel II. Tal actitud provocó en no pocas ocasiones una gran incomodidad entre los diversos sectores liberales, agudizada por las actitudes políticamente retrógradas de gran parte de la administración patrimonial. La constante vulneración cuando no incumplimiento por parte de ésta de las normas dictadas por las Cortes alentó acusaciones de connivencia con los sectores carlistas, con todo lo que esto comportaba, y una aguda conflictividad social, especialmente en el ámbito mediterráneo, allí donde los bienes y derechos patrimoniales presentaban una estructura y naturaleza más arcaica y señorial 5 .

El triunfo finalmente del Estado constitucional, aunque tibiamente representativo, a partir de 1844, se impuso a pesar de los obstáculos interpuestos por la institución monárquica. Liderado por el moderantismo y con la constante oposición de las fuerzas progresistas, el encaje de la monarquía en la nueva realidad hubo de hacerse desde supuestos distintos a los de Cádiz, dejando un amplio margen a la legitimidad histórica y sobre la base de la soberanía compartida Rey-Cortes. Isabel II (1843-1868) heredó de su madre a una temprana edad no sólo el trono, sino también un complejo, diverso y, en muchos sentidos, arcaico patrimonio, contra el que se estrellaron reiteradamente los intentos de modernización y racionalidad administrativa (impulsados incluso por sectores del liberalismo nada sospechosos de radicalidad) y sobre todo las recurrentes críticas y propuestas del progresismo para su reforma y abolición. A ello se sumaría, como una pesadilla para la nueva reina, la mala resolución de la testamentaría de su padre, manipulada y tergiversada por María Cristina, y que extendería sobre la Corona española un manto de suspicacias, acusaciones de ambición y de agiotismo, de netas y contundentes repercusiones políticas. No en vano, la ya ex regente hubo de abandonar el país y ceder su puesto al general Espartero en 1840, envuelta en un manto de críticas, que se reiterarían en 1854 de la mano de una comisión parlamentaria encargada de investigar sus actuaciones. De la misma manera, Isabel II perdería el trono en 1868 en un contexto cuyo telón de fondo venía marcado por las contundentes críticas al Patrimonio Real y por las acusaciones de robo de las joyas de la Corona. Asuntos supuestamente privados o, cuando menos, que se querían como tales, interferían en la esfera pública, al tiempo que desde la política la monarquía y sus titulares se veían

5 Sobre la aguda conflictividad social desencadenada por la cuestión patrimonial tras la muerte de Fernando VII, ver GARCÍA MONERRIS, Encarna «Real Patrimonio y resistencias antifeudales en el País Valenciano (1834-1843)», in Estudis d'Història del País Valencià, 4, 1983, pp. 99-131. 
permanente expuestos y cuestionados. Aunque la fe monárquica no quebró en ninguna de las dos grandes familias liberales, sí que lo hizo la dinástica, propiciando de esta manera la confrontación de proyectos e imaginarios diversos de monarquía. Esto se hizo patente por primera vez durante la coyuntura revolucionaria del denominado Bienio Progresista (1854-1856), y se acentuó a partir de $1865^{6}$.

En un contexto de crisis económica y en un momento en el que la credibilidad de Isabel II y su relación con el moderantismo no pasaba por los mejores momentos, desde sectores de ese mismo espectro ideológico se quiso salir al paso de lo que a todas luces era una necesidad política: reconciliar a la reina no sólo con sus tradicionales aliados, sino con el conjunto de la nación. Fue aquí donde el Patrimonio Real pasó a tener de nuevo un protagonismo de primer orden. El carácter ambiguo de su naturaleza jurídica, que se había mantenido a lo largo del tiempo, quiso ser clarificado mediante la constitución de una parte del mismo como vínculo o Patrimonio de la Corona; el resto, desde una supuesta magnanimidad de la reina, sería entregado a la nación para su venta, pero reservándose aquella el 25 por ciento del importe de la misma. Era la manera legal y políticamente correcta de poder desprenderse de un patrimonio que, mal gestionado, generaba más gastos que ingresos. Pero no era la nación la que por su iniciativa recobraba un patrimonio propio, sino la reina la que en un gesto de supuesta magnanimidad y desde su condición de "propietaria”, le cedía una parte de aquel. Era la última desamortización que se efectuaba en España, pero la primera, curiosamente, impulsada por el moderantismo y los sectores más cercanos a la reina, y que tuviera que ver con bienes del Real Patrimonio. El progresismo y el republicanismo, que tanto habían luchado a lo largo de los años 30, 40 y 50 por una solución soberanista y desamortizadora, se vieron confrontados a la realidad de una iniciativa que era tomada por sus oponentes políticos y que, en teoría, estaba destinada a reforzarlos y a convertirlos en beneficiarios políticos de la operación. Ahora, lo único que podían reclamar los progresistas, desde una posición de resignación, era que se delimitasen claramente qué bienes debían componer el patrimonio de la Corona y cuáles correspondían a la nación.

\footnotetext{
${ }^{6}$ Para todo el reinado de Isabel II es imprescindible el libro de BURDIEL, Isabel, Isabel II. Una biografía (1830-1904), Madrid, Taurus, 2010; para el período del Bienio Progresista, además, ID., Monarquía y Nación en la cultura política progresista. La encrucijada de 1854, in GARCÍA MONERRIS, Encarna, MORENO SECO, Mónica, MARCUELLO BENEDICTO, Juan L. (eds.), Culturas políticas monárquicas en la España liberal. Discursos, representaciones y prácticas (1808-1902), Valencia, PUV, 2013, pp. 213-232. En este mismo libro, y a propósito del intrincado asunto de la testamentaría de Fernando VII, GARCÍA MONERRIS, Encarna, GARCÍA MONERRIS, Carmen, ¿̇Interés de familia u objeto político? La testamentaría de Fernando VII, in GARCÍA MONERRIS, Encarna, MORENO SECO, Mónica, MARCUELLO BENEDICTO, Juan L. (eds.), op. cit., pp. 177-211.
} 
Sus tibias críticas fueron superadas, como era de esperar, por las del republicanismo, especialmente encarnado en dos artículos de Emilio Castelar en el periódico «La Democracia». En uno de ellos se decía: «el Patrimonio Real se desamortiza: victoria grande, sí, pero victoria exclusiva de la democracia que ha venido sosteniendo esta desamortización por espacio de mucho tiempo»7. Lejos, pues, de ser resultado de la mera voluntad de la reina, la operación se quería hacer ver por parte de los sectores más radicales como el resultado necesario e ineludible de un largo proceso de lucha por la recuperación de unos bienes que se consideraban patrimonio de la nación. El que este político y periodista denominó como «El rasgo», en lugar de reforzar la imagen de la monarquía, contribuyó poderosamente a su deterioro y descrédito. Más allá del litigio acerca de la titularidad de los bienes patrimoniales (que la ley de 1865 otorgaba al monarca) el supuesto desprendimiento no pudo evitar las salpicaduras de egotismo y acto interesado económicamente, simbolizado en el 25 por ciento que se reservaba la reina.

Los acontecimientos que desencadenaron la revolución de septiembre de 1868 y la caída de la monarquía isabelina, representaron la imposibilidad del proyecto progresista de una monarquía abrazada por la nación, al tiempo que mostraban las limitaciones y errores de un moderantismo oligárquico empeñado en el secuestro de la institución para sus propios intereses partidistas. La crisis finalmente no destruyó del todo la opción monárquica, pero sí la dinastía de los Borbones. Tras el impase casi republicano que se abrió a partir de septiembre de 1868, las fuerzas septembristas, especialmente el progresismo, pudieron retomar su anhelado proyecto de maridaje entre la nación y una monarquía que, ahora sí, debía basarse en una legitimidad estrictamente política y ser plenamente nacional. Antes incluso de solucionarse el problema de la titularidad del trono (que como sabemos acabó recayendo en el rey Amadeo, de la casa de Saboya) el tema del patrimonio regio y del recién constituido vínculo de la Corona volvió a ocupar, una vez más, amplísimos espacios en las sesiones de las Cortes, forzando una vuelta de tuerca orientada hacia la liquidación definitiva del vínculo recién creado. La ley de diciembre de 1869, debida al progresista y librecambista ministro de Hacienda Laureano Figuerola, saldaba cuentas con la anterior de $1865 \mathrm{y}$, en realidad, con todo el periodo histórico precedente. Definitivamente desaparecían los lazos y las relaciones, por muy tenues que hubieran sido, entre la monarquía y su patrimonio histórico, viéndose obligada ahora a asentarse

7La Democracia, 21 de febrero de 1865. Corresponde la cita al artículo de Emilio Castelar «¿De quién es el Patrimonio Real?». El 25 del mismo mes publicaría en ese periódico otro conocido con el título de «El rasgo», que acabó dando nombre popular a toda la operación. 
sobre una única legitimidad política que simbolizaba la Constitución de 1869 y la "lista civil". Sólo desde esta condición, que acababa con las ambigüedades de un patrimonialismo siempre caracterizado por la confusión entre lo público y lo privado, pudo reconocerse en la ley por primera vez la condición "privada" del titular de la Corona $\mathrm{y}$, en consecuencia, su total legitimidad para el uso y administración de caudales privados. También esta ley quiso contribuir, por tanto, a deslindar con claridad lo político y público de la monarquía respecto de su esfera privada.

El proyecto de ley de Figuerola tenía, en efecto, tres títulos, cuyo orden reflejaba perfectamente el principio soberanista de la disposición y el sentido de inversión de las prioridades entre la anterior y esta ley. El primero se titulaba De los bienes que se declaran del Estado y de su venta y aplicación; el segundo, De los bienes que se destinan al uso y servicio del rey; y el tercero, Del caudal privado del rey ${ }^{8}$ La discusión de este proyecto y de su posterior dictamen, generó un interesantísimo debate a propósito de los espacios y lugares que la nación debía reservar al nuevo rey, procedentes del antiguo patrimonio. Curiosamente, si en 1865 había interesado especialmente el carácter económico de la operación desamortizadora y los beneficios criticables que la propia reina se disponía a sacar de ella, ahora, cuando una gran parte del patrimonio había sido ya enajenado y habían sido redimidos o abolidos una gran cantidad de sus derechos, censos y privilegios, lo que pasó a primer plano fue un tema tan importante para la nueva monarquía como su "arropamiento" por los nuevos edificios y espacios que la nación le iba a reservar. Se ponían así sobre la mesa imágenes y proyectos diversos de monarquía. Las distancias muchas veces parecían marcarse, ya no con una opción determinada de monarquía constitucional, sino con una monarquía considerada casi de Antiguo Régimen a la que debería contraponerse un rey «democrático que ha de aplicar la Constitución de 1869»9:

[...] ya no necesitamos reyes que pasen la primavera en Aranjuez, el verano en San Ildefonso, el otoño en San Lorenzo y el invierno en el Pardo. El rey que debe venir para aplicar la Constitución de 1869 debe ser un rey ilustrado, y que ocupe el tiempo, no cazando jabalíes, ni buscando bellotas para cebar cerdos y después matarlos en Aranjuez, sino que ha de ser un rey ilustrado, que se dedique a los

8 Diario de Sesiones de Cortes (D.S.C.), sesión de 5 de julio de 1869, Apéndice segundo al número 118. También Archivo General de las Cortes (A.G.C.). Expedientes Generales, 147-12, donde se recoge la documentación generada en el todo proceso de tramitación de la ley.

9 D.S.C., sesión de 26 de noviembre de 1869, p. 4394. 
libros y que examine y conozca el estado de la nación, y que solo necesite una casa decentemente puesta con un jardín para recreo y esparcimiento ${ }^{10}$.

La casuística del proyecto de ley escondía en realidad imaginarios distintos de monarquía. Discutir sobre qué espacios y lugares debían albergar su figura y representar a la institución era una forma de diseñar y prefigurar no sólo elementos ornamentales o exteriores, sino proyectar sobre ellos valores y virtudes que se predicaban de la persona que debía representar la nueva dinastía. Y a la inversa: el rey imaginado debía guardar una ejemplaridad y concordancia con los lugares que, a fin de cuentas, marcaban su presencia.

Esta discusión se convirtió por momentos en una competencia entre diputados defensores del valor simbólico e histórico de determinados edificios enclavados en sus respectivos territorios. El Alcázar de Sevilla, tras una larga discusión, fue finalmente integrado en la ley, como parte de los lugares regios; la Alhambra de Granada se pretendió también, en un determinado momento, convertirla en residencia real, lo mismo que el palacio de la Aljafería de Zaragoza. Sin embargo, además del Alcázar sevillano, los dos únicos nuevos sitios que se reconocieron en la ley fueron el castillo de Bellver y el Palacio de la Almudaina en Mallorca $^{11}$.Tal vez el diputado que mejor y más brillantemente supo trascender lo concreto de este debate, explicitando sus claras derivaciones políticas y simbólicas, fue el mallorquín Enrique de Cisneros. La monarquía de la que estaban tratando era ya una monarquía "abrazada por la Nación”, constitucional y hermanada con las entidades representativas. Por eso mismo, la dignidad regia era también "la dignidad de la nación", tomando como referencia el ejemplo inglés. Los edificios tenían un papel cultural y simbólico que no debía despreciarse: era la forma de engarzar la dinastía con la historia patria; era un forma de engarzar presente con pasado, pero «no por medio de derechos que han caducado, no concediendo al rey privilegios abolidos e incompatibles con nuestras instituciones y con los adelantos del siglo, sino echando sobre sus hombros la brillante sobreveste de la

\footnotetext{
${ }^{10}$ Ibidem.

${ }^{11}$ Los sitios reales reservados en la ley de 1869 eran prácticamente los mismos que en 1865 constituían el vínculo de la Corona, pero con una delimitación geográfica y de sus entornos mucho menor y más ajustada. Eran el Palacio Real de Madrid, el Campo del Moro, la Plaza de la Armería, caballerizas y cocheras, excluyendo la Plaza de Oriente y sus jardines; la Casa de Campo, el Sitio del Pardo (exceptuando algunos cuarteles), el Palacio de Aranjuez y sus jardines, el Monasterio de San Lorenzo de El Escorial y dependencias adjuntas; el Palacio de San Ildefonso y jardines, el Coto de Riofrío y sus edificios, el Alcázar de Sevilla, el Castillo de Bellver y el Palacio de la Almudaina en Mallorca. Estos serían los mismos sitios reales que mantendría la posterior ley de restauración del vínculo o patrimonio de la Corona de Alfonso XII en 1876, a los que añadirían los patronatos e iglesias que la ley progresista de 1869 había querido abolir.
} 
gloria nacional»12. Desde la perspectiva de una monarquía nacional en el sentido más literal de la palabra, no podía consentirse «que todas las fincas destinadas al rey estén situadas dentro de los límites del antiguo reino castellano, y no tenga casa aquel en los dominios de la antigua Corona de Aragón»13. La nación española se configuró a través de dos momentos claves: la Reconquista y la unidad política con los Reyes Católicos. El primer hecho estaba simbolizado por el Alcázar de Sevilla; el segundo, el de la unidad, exigía necesariamente la presencia de monumentos y edificios enclavados en la antigua Corona de Aragón. Entre ellos, se eligió el Castillo de Bellver y el Palacio de la Almudaina en Mallorca, sitios cargados, por lo demás, de recuerdos tan memorables para el liberalismo como el encierro del ilustrado Gaspar Melchor de Jovellanos o el fusilamiento del general liberal Lacy ${ }^{14}$.

Aprobada la ley, quedaba por dilucidar en las Cortes constituyentes la dotación para la nueva monarquía, es decir, la "lista civil", aquello que desde los inicios del constitucionalismo había marcado, al menos teóricamente, su carácter constituido, su inclusión en la red institucional del Estado y de la nación. En la práctica, sin embargo, como hemos visto, el tema había estado siempre contaminado por la indeterminación de la naturaleza de los bienes patrimoniales, su permanencia, la voluntad de sus titulares de mantenerlos como bienes privativos y la dificultad o torpeza de los políticos a la hora de orquestar una solución consensuada sobre el tan manido tema a lo largo del siglo XIX. No ayudó tampoco la posición de algunos sectores del moderantismo que seguían considerando la "lista civil" como una "servidumbre" inadmisible e indigna de la monarquía respecto a los presupuestos. El progresismo, por el contrario, soportó como una ambigüedad o contradicción la permanencia de la dualidad "lista civil"rentas patrimoniales, sobre todo cuando sobre estas últimas no se aplicaron casi nuca criterios de trasparencia y de racionalidad. Desaparecido el Patrimonio Real definitivamente con la ley de 1869, era el momento de marcar distancias con la concepción de la monarquía anterior. De hecho, ya desde 1865, este sector político había planteado la cuestión como una disyuntiva entre «patrimonio» o «dotación» 15. Las fuentes de mantenimiento de la Casa Real sólo podían ser dos: o las rentas y bienes derivados del patrimonio, o la dotación de la lista civil. «O Patrimonio o dotación, pero el Patrimonio como propiedad nacional, administrado por la nación»16. De lo contrario,

${ }_{12}$ Toda la discusión sobre este interesante aspecto en D.S.C., sesión de 3 de diciembre de 1869, pp. 4517-4530.

13 Ibidem.

14 Ibidem.

15 Entre esos términos se desplegaban los argumentos de los artículos aparecidos en «La Soberanía nacional» el 24, 25 y 27 de febrero de 1865.

16 Ibidem. 
seguir insistiendo en su carácter privado, retrotrae, según el periódico progresista, a aquella época de los bárbaros en que los reyes conquistaban sus territorios y mantenían al resto del pueblo en condición de vencidos. Todo lo contrario a lo que ya había establecido la temprana Constitución gaditana. De manera más convincente, declaraba que:

Del Patrimonio real a la dotación de la Casa real hay la misma distancia que hubo del estado feudal, de la Edad Media, al Estado constitucional o Edad Moderna. Son dos principios, dos edades, dos épocas, dos civilizaciones, dos derechos muy distintos, diametralmente opuestos; o uno u otro; no cogen, no caben juntos, se excluyen ${ }^{17}$.

Sólo tras las leyes desamortizadoras de 1865 y 1869 empezó a hacerse realidad la separación entre Patrimonio y Real Casa: esta última sólo tenía relación con aquel por lo que respecta a aquellos sitios, palacios o jardines que las Cortes y el Gobierno le hubieran asignado para su dignidad, uso y recreo. Sin olvidar que, también a partir de entonces, la derivada no menos importante de la posibilidad de una fortuna personal podía y debía discurrir por cauces estrictamente privados y civiles, como la de cualquier otro ciudadano. Cuando se discutió la "lista civil" del nuevo monarca Amadeo I de Saboya se tuvo en cuenta tanto la dotación del mismo como la de otras casas reinantes en Europa, así como la novedad de la inexistencia ya de rentas patrimoniales. El país había ganado con la venta del Patrimonio Real, pero se seguía considerando la necesidad de una dotación inferior a la que tuvieron los reyes de la dinastía anterior. Concretamente, un presupuesto de 7,5 millones de pesetas, de los cuales 6 eran de lista civil en sentido estricto, es decir, asignación personal al rey; medio millón de dotación del príncipe heredero y un millón para conservación de los edificios que las Cortes habían confiado a la Corona ${ }^{18}$.

En medio de acaloradas intervenciones de los miembros de las Cortes a propósito del Patrimonio Real y de la "lista civil", cuando ya la cuestión se dejaba zanjada y deslindada con claridad, volvió a emerger otro viejo conflicto que tenía que ver con las joyas de la Corona. Era este un tema que se consideraba que formaba parte del vínculo de la institución y que, en consecuencia tenía su relación directa con el tema patrimonial. A su vez, se relacionaba de manera explícita con el testamento que el rey Fernando VII había dejado escrito, acompañado de un supuesto inventario de las joyas

17 Ibidem.

18 «Proyecto de ley, presentado por el Consejo de Ministros de S. A., sobre consignación de la Casa Real», D.S.C., sesión de 20 de diciembre de 1870, Apéndice 1 al número 321. 
existentes en palacio en el momento de su muerte. La turbia gestión que de la testamentaría hizo la regente María Cristina, así como la desaparición del inventario fernandino, se tradujo en una intencionada falta de claridad entre bienes de libre disposición y bienes vinculados a la Corona. De hecho, en las sucesivas ejecuciones de dicha testamentaría, hasta la casi definitiva transacción realizada en 1858, se abusó extraordinariamente del carácter de bienes de libre disposición, entre los cuales siempre se tuvo la sospecha de la existencia de una gran cantidad de joyas que, o bien fueron sustraídas por María Cristina, o bien habían ido a parar a manos de sus hijas. Cuando Isabel II, en 1868 marchó al destierro parte de la prensa le acusó de ir "acompañada" de una gran cantidad de estas joyas que, en realidad, pertenecían a la Corona ${ }^{19}$.

Realidad o no, el caso es que el tema tenía una carga simbólica extraordinariamente potente que resaltaba su valor político. Aunque el asunto, en sentido estricto, no tenía por qué haber interferido en la abolición del Patrimonio Real en 1869, lo cierto es que lo hizo y con virulencia. El impulsor de la ley, Figuerola, en un momento determinado lanzó en el hemiciclo una dura acusación de robo contra Isabel II, que acabó convirtiéndose en un ataque a toda la dinastía de los Borbones. Lo que estaba en juego no era tanto el valor en sí del objeto de discusión, cuanto el hecho de que una minusvaloración de la última reina suponía un reforzamiento de la alternativa monárquica que ahora se defendía, encarnada en una nueva dinastía. «Las alhajas de la Corona - empezó diciendo - han sido robadas, y robadas de la manera más escandalosa, porque puede decirse que ha sido un robo doméstico». Las palabras eran muy intencionadas y medidas en su justo significado: se estaba en presencia de un presunto delito, de neta repercusión política, pero pertrechado en el espacio privado, lo cual enterraba cualquier indicio o resto de dignidad que pudiese quedar entre los miembros de la familia real2o. Las posibles dimensiones del problema quedaban agrandadas ante la opinión pública por el descubrimiento de un ámbito reservado, familiar, que lejos ser de un reflejo de la dignidad inherente a la vertiente pública de la institución, espejo de las virtudes que se predicaban para la sociedad, parecía ser un oscuro arcano en el que ocurrían los más inconfesables delitos. La situación ahora para

19 Ver el artículo citado más arriba a propósito del tema de la testamentaría fernandina. Además, detalladas referencias al mismo problema y a sus sinuosos derroteros en COS-GAYÓN, Fernando, Historia jurídica del Patrimonio Real, Madrid, Imprenta de la Riva, 1881.

${ }^{20}$ Este descrédito se sumaba a los escándalos de la vida privada y sexual de la reina y de la Corte, intencionadamente aireados y manipulados por los intereses políticos de los partidos. Al respecto se puede verse la edición e introducción de Isabel Burdiel a Los Borbones en pelotas: BURDIEL, Isabel (ed.), Los Borbones en pelota, Zaragoza, Inst. Fernando el Católico, 2012. Sobre la imagen de la reina, también VILCHES, Jorge, Isabel II. Imágenes de una reina, Madrid, Síntesis, 2007. 
la dinastía era mucho más dramática e irreversible que durante el Bienio. Para las fuerzas políticas que habían propiciado la destitución de la reina, la necesidad de justificación era mucho más apremiante, así como la urgencia de sacar fuera del hemiciclo el problema: «iOjalá que la España entera pudiese asistir a las indicaciones que se están haciendo sobre la Casa Real, para que conociera hasta qué punto España ha tenido necesidad de expulsar la dinastía de los Borbones!»²1. Sólo con estos referentes puede entenderse la desmesura de las intervenciones del ministro de Hacienda en un tema que, indudablemente mal llevado y de difícil solución, arrastraba fuertes implicaciones simbólicas y políticas ${ }^{22}$.

La minoría republicana de las Cortes no reparó en acusar de inconsecuente al gobierno septembrino. Si lo dicho por el ministro era cierto, los culpables debían ser llevados ante los tribunales, del mismo modo que se haría con un «pobre padre de familia»23. Toda la magia y el misterio de la monarquía quedaban rotos:

\begin{abstract}
Querer decir al país que los monarcas que han regido los destinos de España han cometido delitos no vulgares, sino delitos extraordinarios, delitos de los que llamaban nuestras antiguas leyes crímenes, y no tener al mismo tiempo valor cívico para decir al país: nosotros que conocemos estos hechos vamos a abrir sobre ellos la información correspondiente y vamos a llevarlos a los tribunales, para que éstos, depurando la verdad, impongan el condigno castigo a las personas que hayan sido autoras de estos delitos 24 .
\end{abstract}

En sentido contrario, el espectro reaccionario y carlista, desde el primer momento se empeñó en una curiosa exculpación de la familia Borbón, postura que permitió su confluencia con la del grupo liderado por Antonio Cánovas del Castillo, empeñado ya en resucitar el viejo proyecto unionista de restauración de la dinastía borbónica en torno a la persona del hijo de Isabel II, el futuro Alfonso XII (1874-1885).

La prensa conservadora y progresista se enzarzó en acusaciones mutuas, insistiendo la primera en la naturaleza privada de las joyas y en la magnanimidad constante de la reina. La prensa extranjera se hizo eco también de la polémica, manteniendo en general, especialmente en Francia, una actitud más benévola hacia Isabel II. El mismo Napoleón III llegó a mostrar ante el embajador de España en París, Salustiano Olózaga, «su descontento por las acusaciones que en las Cortes ha hecho el señor Figuerola

${ }^{21}$ D.S.C., sesión de 1 de diciembre de 1869, p. 4478.

22 Ibidem.

23 D.S.C., sesión de 1 de diciembre de 1869, p. 4490.

24 Ibidem. 
contra su tío José (I), rey de España, respecto a la desaparición de los diamantes y joyas» 25 .

Un dictamen en las Cortes propuso la creación de una comisión parlamentaria encargada de averiguar «los actos en virtud de los cuales han desaparecido del palacio de los reyes de España, que habitaron los Borbones, las alhajas y efectos que pertenecer debían al patrimonio de la Corona, proponiendo a las Cortes lo que entiendan justo y procedente en reivindicación de ese patrimonio y en desagravio de la ley y de la Nación» ${ }^{26}$. La discusión en torno a la conveniencia o no de esta comisión volvió a enfrentar dos proyectos distintos de monarquía y dos formas de entender la reubicación de esta institución en la España liberal; dos formas distintas de entender la relación entre Monarquía y Nación en un momento de evidente crisis del liberalismo oligárquico, de empuje de las fuerzas democráticas y de evidente avance de la nacionalización. Una vez más, Figuerola y Cánovas personificaron estos proyectos alternativos.

En la discusión que tuvo lugar los días 13, 14 y 15 de diciembre de 1869, la intervención del jefe de las filas conservadoras optó inicialmente por un planteamiento histórico, intentando demostrar la inexistencia de bienes vinculados. El vínculo como tal fue establecido a partir de Carlos III (1759-1788), aunque la posterior invasión y expolio por parte de las tropas francesas había dejado sin contenido el mismo. En cualquier caso no era esto lo más urgente, sino poner en evidencia la trascendencia política del tema y el peligro que encarnaba para la propia monarquía. En este debate lo realmente importante y urgente era salvar la opción monárquica frente a la amenaza republicana. Para ello había que diluir las diferencias dentro de los monárquicos, independientemente de la opción dinástica que los separara. Pero su alternativa tenía también un neto perfil antidemocrático. Sobre la República y sobre las fuerzas políticas republicanas se proyectaban todas las esperanzas y utopías de la amenazante muchedumbre. «todas las pasiones insaciables [...] que la sociedad humana está condenada [...] a no satisfacer jamás»27; utopía religiosa que atentaba contra cualquier culto positivo; utopía económica que confiaba en resolver los conflictos entre capital y trabajo; utopía política basada en la creencia de la igualdad; en definitiva, todas las "utopías sociales" que nunca morirían a pesar de las aparentes derrotas de aquellos destinados a su cumplimiento o realización.

25 Información recogida en La Correspondencia, 10, 13 y 17 de diciembre de 1869.

${ }^{26}$ D.S.C., sesión de 9 de diciembre de 1869 . Apéndice segundo al no 179.

${ }_{27}$ D.S.C., sesión de 14 de diciembre de 1869, pp. 4703-4725. 
Para hacer frente a este peligro, debía alcanzarse una gran conciliación monárquica que reuniera bajo una misma bandera a «las clases conservadoras y todos los grandes intereses del país»28. Una monarquía parcial «será una monarquía perdida, peor que la peor de las repúblicas» ${ }^{29}$. El proyecto, sin embargo, pasaba, entre otras cosas, porque la mayoría de esos momentos renunciara a su idea de seguir arremetiendo contra las diversas casas reinantes, presentándolas como "criminales" y utilizando las mismas armas difamatorias que la muchedumbre. Atacar una dinastía, fuera la que fuera, era en el fondo socavar cualquier posibilidad de opción monárquica verdadera, lanzarse en brazos de la república y estimular «el innato espíritu que hay en las clases bajas de difamación y calumnia contra todo lo que es alto, contra todo lo que es excepcional, contra todo lo que representa necesaria e inevitablemente las limitaciones sociales ${ }^{30}$.

Por parte de la mayoría gubernamental, sin embargo, se esgrimió una convicción moral positiva de la realidad de un robo pertrechado no sólo por la última reina, sino también por su madre María Cristina. Sus argumentos, por tanto, no tenían por qué desprestigiar a la monarquía, sino a dos personas concretas, de una dinastía concreta. La acusación

gravita sólo en desprestigio de la dinastía caída; nosotros queremos purificar la atmósfera, lo mismo que quisieron hacer en 1854 el señor Cánovas y sus amigos. Nosotros creemos en la bondad de la institución monárquica; lo que queremos es evitar, cerrar la puerta a toda clase de restauración, porque no habría cosa más funesta para nuestra patria como una restauración como la del año 14 y como la del año $23[\ldots]^{31}$.

Para ellos, y concretamente para Figuerola, se trataba, por tanto, de recobrar el sueño de la monarquía tantas veces intentada, especialmente en 1854; el sueño de una monarquía auténticamente nacional, imposible ya de encarnarse en los Borbones. Por eso rehuían el término restauración, algo que presentaba connotaciones absolutistas que retrotraían a experiencias poco gratas a la familia liberal en su conjunto. La restauración dinástica carecía de sentido para los progresistas desde el momento en

\footnotetext{
${ }^{28}$ Ibidem.

29 Ibidem.

${ }^{30}$ Ibidem.

${ }^{31}$ Ésta y el resto de la intervención de Figuerola en D.S.C., sesión de 15 de diciembre de 1869, pp.4727-4757. Todas las intervenciones del ministro respecto al tema de las joyas fueron publicadas bajo el título de Discursos pronunciados por el Excmo. Sr. D. Laureano Figuerola, ministro de Hacienda, en las Cortes Constituyentes con motivo de la desaparición de las alhajas de la Corona, en las sesiones de los días 1,2 y 15 de diciembre de 1869, Madrid, Imprenta de M. Tello, 1870 .
} 
que no creían en ese tipo de legitimidad histórica y familiar, sino sólo en la política: «Yo no reconozco legitimidad en otro Príncipe que en aquel que jure la Constitución de 1869[...] Aquí no puede haber más legitimidad que la de la soberanía nacional, ni más origen que la Constitución del 69»32. Pero las circunstancias propiciaban que esa legitimidad no naciera «sólo del voto de las Cortes constituyentes sino también de la demostración de los abusos que han hecho necesario la caída de la anterior dinastía»33. De alguna manera, en estas palabras se condensaba la razón última por la cual los progresistas tenían necesidad de reabrir de nuevo el caso de las joyas y de entroncar con la no concluida discusión de 1856. Les iba en ello una justificación más de su proceder con la dinastía destronada y, sobre todo, por contraposición, con el proyecto anhelado de una nueva monarquía.

Sin embargo, cuando Cánovas hablaba de legitimidad se refería siempre a la de la institución, no a la de los reyes que la encarnaban. Desde este punto de vista, se dijera lo que se dijera, atacar a una dinastía perjudicaba el prestigio de aquella; un prestigio que no podía sostenerse sin tradiciones, sin antecedentes, sin vínculos de nacionalidad. Lo contrario era similar a defender una suerte de monarquía en el vacío, que invalidaría incluso la legítima aspiración de reimplantarla. Los progresistas seguían insistiendo, por el contrario, en una legitimidad de tipo político que hacía que cualquier opción dinástica podía ser buena en el marco de la Constitución de 1869 y de las Cortes Constituyentes; cualquier opción dinástica, excepto la de los Borbones, propugnada ya subrepticiamente por Cánovas, porque había sido contra ellos contra quienes se había levantado "la España con honra" que quiso simbolizar la Revolución de 1868:

\begin{abstract}
tenemos claramente definido nuestro ideal de Monarquía en la Constitución de 1869. Nosotros buscamos un rey para esa Constitución; nosotros no hacemos una Constitución para tal o cual rey; y si no encontramos, si no hubiera medio de encontrar Monarca para la Constitución de 1869, creo que todos tendríamos el valor y la dignidad suficiente para perecer envueltos en las ruinas de esa Constitución antes que nombrar un Monarca que nos obligue a acepta una Constitución diferente34.
\end{abstract}

Como ya sabemos, Amadeo I de Saboya fue ese rey para esa Constitución. Pero aquellas fuerzas que lo apoyaron, especialmente los progresistas, acabaron, en efecto, muriendo envueltos en sus ruinas y expuestos tras la abdicación del monarca a ser

\footnotetext{
32 Ibidem.

33 Ibidem.

34 D.S.C., sesión de 2 de junio de 1876, pp. 1888-1894. 
superados por la solución republicana. La comisión parlamentaria que se nombró no tuvo ningún efecto ante la vorágine de los acontecimientos $\mathrm{y}$, sobre todo, la preocupación de las Cortes republicanas por proceder a la liquidación de cuanto sonase a Patrimonio Real. Durante breve tiempo, aquel, coyunturalmente convertido en Patrimonio de la Corona por la ley de 1865 y abolido luego por la de 1869, pasó a ser un Patrimonio Nacional que osciló entre la buena voluntad de las fuerzas republicanas de evitar su deterioro y la realidad que impuso la virulencia revolucionaria y de los conflictos políticos del momento. El Archivo y la Biblioteca del Palacio Real pasaron a formar parte, como todo un símbolo, de la Biblioteca y Archivo de las Cortes. La memoria histórica de la monarquía pasaba a ser custodiada y administrada por el máximo órgano de representación de la soberanía y de la nación. Por su parte, el afán desamortizador sobre edificios, terrenos y viejas propiedades siguió adelante, especialmente en Madrid y su provincia.

La Restauración alfonsina, tras el golpe de estado del general Martínez Campos en diciembre de 1874, quiso ser no sólo una estabilización definitiva y una opción civilista del régimen liberal, sino una nueva reconciliación de la nación con la monarquía, pero, eso sí, de la tradicional dinastía borbónica y sin la legitimidad democrática que pudiera otorgarle la Constitución de 1869, sustituida por la nueva de 1876. El binomio entre legitimidad política y legitimidad histórica volvió a concretarse en la dualidad que representaba la "lista civil" y un restaurado "patrimonio de la Corona". La recuperación, bien que sólo fuera jurídica y simbólica del carácter vinculado y patrimonial de aquellos espacios y territorios que iban a ser ocupados por la nueva monarquía, implicaba el retorno a su tradición más sustantiva y corpórea, que ligaba a la institución con sus propias e históricas posesiones. Paradójicamente, la nacionalización de la nueva monarquía soñada por Cánovas se hacía sobre la "desnacionalización" de un viejo patrimonio del que, no obstante, quedaba ya muy poco. El mismo hecho de que un único proyecto de ley, presentado por el ministro de Hacienda el 22 de abril de 1876, abordara por primera vez de manera conjunta la "lista civil y las «posesiones patrimoniales», suponía el intento de aplicar una vez más el modelo inglés de calcular el monto de la primera teniendo en cuenta la rentabilidad de aquellos bienes y fincas vinculados de nuevo a la Corona35.

Es cierto que históricamente, desde el mismo momento en que se instauró la monarquía constitucional, era inevitable tratar ambos aspectos a la vez. Indirecta o solapadamente, así ocurrió muchas veces. Pero nunca hubo la capacidad ni la

35 Sobre el modelo inglés, ver el trabajo de KUHN, William M., «Queen Victoria's civil list: What did she do with it?», in The Historical Journal, 36, 3/1993, pp. 645-665. 
posibilidad de un tratamiento interrelacionado que planteara globalmente la nueva dimensión política de la monarquía y sus necesidades en el nuevo orden, y diera una solución racional al tema de los antiguos bienes de la Corona. La radicalidad de la opción soberanista del primer período constitucional, por una parte, y la deriva no menos radical en un sentido privativo del patrimonio en época de Fernando VII, por otra, condicionaron extraordinariamente el debate y la resolución (o mejor, no resolución) del tema durante décadas. A ello cabría añadir, como no menos condicionante, la imposibilidad de criterios trasparentes y de racionalidad contable y administrativa en el seno de la Casa Real y del Patrimonio; algo que se intentó con más o menos fortuna con Agustín Argüelles, tutor de Isabel II y el intendente de Palacio, Martín de los Heros, en la década de los 40. Habría que esperar a la crisis definitiva de la monarquía isabelina para que la Corona dejara de controlar de manera directa su viejo patrimonio. El "rasgo" fue una manifestación más (aunque de efectos no previstos) de esa vieja concepción patrimonial y privada. En cualquier caso, tratamiento de la lista civil y realidad patrimonial siguieron a lo largo del siglo XIX cada uno por su lado. Ahora, sin embargo, cuando quien dispone qué hacer con ese patrimonio son las Cortes, por mucho que se vuelva al viejo concepto de Patrimonio de la Corona, es posible y deseable un tratamiento conjunto e interrelacionado de ambos temas. Era, desde hacía tiempo, la opción y la solución británica, que tantos y tan buenos resultados parecía dar. Aquí, sin embargo, en la práctica, el viejo patrimonio estaba ya considerablemente mermado a resultas de la mala gestión de la administración de la Casa Real, de los procesos desamortizadores de 1865 y 1869, y de su propio deterioro histórico.

Con la Constitución de 1876 los tiempos habían cambiado, pero no lo suficiente como para entroncar con la monarquía nacional y democrática de la Constitución de 1869, sino, por el contrario, para establecer simbólicos aunque inquietantes puntos de conexión con muchos elementos de la vieja Casa Real isabelina. Frente a la casi hiriente austeridad de la asignación de la "lista civil" y, sobre todo, frente al sentido extraordinariamente restrictivo de familia real, en los presupuestos asignados en 1876 a la de Alfonso XII se volvía a contemplar un arcaico sentido amplio de la misma, que incluía no sólo a los Príncipes de Asturias, sino también a Infantes, conyugues, madres y abuelas de reyes. En el mismo sentido, el Patrimonio de la Corona, aunque concretado en los lugares, sitios y palacios tradicionales de la monarquía española, amplió su elenco con la inclusión en el mismo de las instituciones de los Patronatos e Iglesias anteriormente excluidos. 
También en este caso y en este momento, la estrecha relación existente entre proyectos monárquicos y sitios reales volvió a plantearse. Frente a las posturas de la mayoría conservadora sustentadora del proyecto restauracionista se alzaron las voces de la minoría liberal constitucionalista de Práxedes Mateo Sagasta. Correspondió en este caso a un diputado por la provincia de Alicante, Carlos Navarro y Rodrigo, no por casualidad miembro de la Junta Revolucionaria interina de septiembre de 1868 y posterior defensor de Amadeo de Saboya, trasladar a la nueva situación política parte del legado y de aquel proyecto que había constituido la monarquía de origen italiano. En sus palabras resonaron muchas veces ecos del viejo sueño progresista, del que eran herederos, de un monarca austero, ejemplar, modélico y radicalmente enraizado con la realidad de la nación.

El diputado se declaraba conservador en la revolución, un hombre de orden pero de ideas avanzadas, un católico que defendía la libertad de religión y un monárquico que quería una monarquía adecuada a los tiempos. Aspiraba a que la minoría liberal constitucional, «ensanchando sus filas, ensanchando sus horizontes, recogiendo todos los elementos liberales de dentro de la cámara y de fuera de la cámara, [...] yo deseo que esta minoría, ensanchando sus horizontes, venga a atraer, venga a reconciliar a todos los elementos revolucionarios, a todos los elementos liberales que no han renegado de la monarquía, con la monarquía del rey D. Alfonso» ${ }^{36}$. Porque el tiempo había sido, efectivamente, tiempo de revoluciones. $\mathrm{Y}$ en medio de esas revoluciones había tenido y tiene que pugnar la legitimidad monárquica, dejando por el camino muchos de los viejos elementos y rituales de justificación y legitimación. La monarquía ya «no se sostiene como se sostenía antes, con la fe, con la devoción, con el entusiasmo; renunciad al factor del entusiasmo en todos los cálculos políticos en el último tercio del siglo XIX; contentaos con la adhesión fría y serena de la razón, de la reflexión, del patriotismo, de los grandes intereses que constituyen las tramas de las sociedades modernas»37. La trama estaba constituida fundamentalmente por las "clases conservadoras”, para él sinónimo de unas amplias y diversas clases medias. Sobre ellas descansaba la posibilidad y el éxito del proyecto monárquico, siempre y cuando la monarquía supiera convertirse en un fiel reflejo del sentido de orden, medianía, modernidad y razón que adornaban a dichas clases. La lista civil, a su vez, debía ser espejo de esa misma monarquía. ¿Podía ser la lista civil presentada por el Gobierno ese ansiado reflejo, cuando en la misma aparecían de forma detallada los nombres, ya no sólo del rey y de los Príncipes de Asturias, sino de múltiples infantas, de la reina madre,

${ }^{36}$ D.S.C., sesión de 2 de junio de 1876, pp. 1888-1894.

37 Ibidem. 
de su esposo, de la duquesa de Montpensier, e incluso de la reina gobernadora María Cristina de Borbón? En este caso, el detalle resultaba ofensivo y la claridad hiriente. Un detalle y una claridad que exponían a la institución a las «antipatías, malevolencia y odiosidad». La monarquía debía estar inserta en la realidad de los tiempos y la realidad exigía austeridad 38 .

Como si de una metáfora se tratara, una comisión especial se encargó de liquidar las cuentas pendientes entre la vieja Casa Real isabelina y el Estado. Los tiempos eran otros, otro debía ser el papel de esta institución, otra su forma de funcionar y su engarce en el Estado. Y aunque esto se hacía desde el más profundo respeto a los reyes por parte de las dos fuerzas políticas fundamentales de la restauración alfonsina, la conciencia de los cambios que habían recorrido la Europa de las monarquías y, sobre todo, los avisos revolucionarios de comienzos de los setenta, imponían nuevas formas y mecanismos legitimadores. En la discusión entre Cánovas y Navarro a propósito de la "lista civil" de la nueva monarquía restaurada, fue este último el que mejor captó los peligros y el difícil equilibrio en que se sustentaba la forma monárquica en tiempos de revolución:

Yo sé también, señores, que en este siglo, que por desgracia y con razón se llama en la Historia «el siglo de las revoluciones», yo sé que en este siglo las monarquías se han transformado, y despojadas en gran parte de aquella poesía, de aquel misterio, de aquella majestad con que se presentaban en lo antiguo al culto de las muchedumbres, [...], yo creo que las monarquías no son ya para muchos sino como aquellos frontispicios, como aquellas fachadas que los antiguos conservaban en los templos que derribaban para la construcción de los nuevos templos, a fin de mantener el culto, a fin de mantener la devoción y la superstición de las muchedumbres, y dar al templo nuevo algo de la poesía, algo de la tradición, algo del misterio, algo de la majestad clásica del templo antiguo39.

${ }^{38}$ D.S.C., sesión de 2 de junio de 1876, pp. 1888-1894.

39 D.S.C., sesión de 3 de junio de 1876, p. 1888. 


\section{* Los autores}

Encarna García Monerris es profesora Titular del Departamento de Historia Contemporánea de la Universitat de València. Su principal línea de investigación se centra en los aspectos políticos de la crisis del Antiguo Régimen y el primer liberalismo, ocupándose de la naturaleza de la Monarquía absoluta, las identidades políticas y el discurso institucional desde el espacio local, o de la peculiar dialéctica entre los discursos liberales y reaccionarios. Es autora entre otros de $L a$ Monarquía Absoluta y el municipio borbónico (Madrid, Consejo Superior de Investigaciones Científicas, 1991), junto con Justo Serna Alonso de La crisis del Antiguo Régimen y los absolutismos (Madrid, Sintesis, 1994), junto con Carmen García Monerris de La Nación secuestrada (Valencia, PUV, 2008) y coordinadora de Guerra, Revolución, Constitución (1808 y 2008) (Valencia, PUV, 2012).

URL: < http://www.studistorici.com/progett/autori/\#GarciaMonerris_Encarna >

Carmen García Monerris es profesora Titular del Departamento de Historia Contemporánea de la Universitat de València. Su línea de investigación prioritaria está centrada en la crisis del Antiguo Régimen y los orígenes de la sociedad liberal. Ha tratado aspectos como el de la peculiaridad patrimonial de la formación socioeconómica valenciana, la relación entre la Ilustración y el primer liberalismo, o los orígenes de la cultura constitucional en España. Es autora de Rey y Señor (Valencia, Excmo. Ayuntamiento de València, Delegación Municipal de Cultura, 1985), La Corona contra la Historia. José Canga Argüelles y la reforma del Real Patrimonio valenciano (Valencia, PUV, 2005), junto con Encarna García Monerris, La Nación secuestrada (Valencia, PUV, 2008) y coordinadora de Guerra, Revolución, Constitución (1808 y 2008) (Valencia, PUV, 2012).

URL: < http://www.studistorici.com/progett/autori/\# GarciaMonerris_Carmen >

\section{Per citare questo articolo:}

GARCÍA MONERRIS, Encarna, GARCÍA MONERRIS, Carmen, «Monarquía y patrimonio en tiempos de revolución en España», Diacronie. Studi di Storia Contemporanea : Le monarchie nell'età dei nazionalismi, 29/12/2013, URL:< http://www.studistorici.com/2013/10/29/garcia_monerris_numero_16/ >

Diacronie Studi di Storia Contemporanea $\beta$ www.diacronie.it

Risorsa digitale indipendente a carattere storiografico. Uscita trimestrale. redazione.diacronie@hotmail.it

Comitato di redazione: Marco Abram - Jacopo Bassi - Luca Bufarale - Alessandro Cattunar - Elisa Grandi - Deborah Paci - Fausto Pietrancosta - Matteo Tomasoni - Luca Zuccolo

Diritti: gli articoli di Diacronie. Studi di Storia Contemporanea sono pubblicati sotto licenza Creative Commons 2.5 . Possono essere riprodotti a patto di non modificarne i contenuti e di non usarli per fini commerciali. La citazione di estratti è comunque sempre autorizzata, nei limiti previsti dalla legge. 